\title{
Correspondencia cervantina de D. Alberto Sánchez (I)
}

\author{
José CARlos DE Torres*
}

D. Alberto (1915-2003) perteneció aún a las generaciones de estudiosos que se cartearon con amigos y colegas de la profesión intelectual. Además se da la circunstancia de que guardó una gran parte de la correspondencia que le pareció más importante. Se revela en ella lo que fue su vida de profesor y estudioso de la Literatura, así como una parte de la sociedad española a la que perteneció. Gracias a la familia, y de manera especial a su hija Marta, podemos conocer una selección epistolar del mundo cultural en el que se movió, de una manera particular el cervantino en el que fue muy reconocido. La correspondencia corrobora sus estudios y trabajos en Anales Cervantinos.

Los temas de la totalidad de la correspondencia de D. Alberto aluden a su conocimiento sobre bibliografía muy concreta, por tanto leída. La escasez de bibliotecas en las ciudades con Institutos de Enseñanza Media motivaba consultas a D. Alberto. Hasta tuvo que comunicar a autores afectados por la publicación de sus artículos cuando Anales Cervantinos se suspendió temporalmente (los recortes económicos que afectan a veces al Consejo). Los temas son muy variados: hay cartas sobre concursos literarios; una muy particular sobre nombres populares de pájaros en el dominio catalán; comentarios sobre Blasco Ibáñez y de Calderón de la Barca con Cervantes, etc. Y, ¡cómo no!, comentarios muy variados sobre aspectos de la investigación cervantina. $\mathrm{La}$ aceleración en los medios para comunicarse sólo le afectó en los últimos años. El género epistolar apenas ya se acostumbra.

En cuanto a José María Casasayas (1927-2005), jurista y empresario, ajeno por consiguiente al mundo profesional de la enseñanza y de la investigación literaria, su vocación cervantista, y modo de entender el quijotismo en su

\footnotetext{
* CSIC y Asociación de Cervantistas. Madrid.
} 
época, hizo posible la empatía con D. Alberto, a partir de conocerse ambos en la sede del Consejo en Duque de Medinaceli, lo que propició que José María se pusiera en contacto con profesores e investigadores. Así se llegó a fundar la Asociación de Cervantistas.

\section{CORRESPONDENCIA ENTRE D. AlberTo SÁNCHEZ Y JOSÉ MARÍA CASASAYAS}

Las cartas se escribieron entre los años 1976 y 1978. Hay en el paquete de D. Alberto una enviada a su hija Marta al estar convaleciente de la vista; otra, copia de la remitida al prof. Manuel Criado de Val por el congreso cervantino de 1978 en Madrid, y otras de D. José Simón Díaz por el Seminario «Menéndez Pelayo» de la Fundación Universitaria Española, ya que le interesó a José María estar en Madrid cuando D. Alberto lo iba relacionando con profesores que él, por su profesión jurídica, no conocía personalmente, sí desde luego por sus escritos.

Antes de comentar la correspondencia como índice y reproducirla hay que decir algo de cómo se conocieron ambos y sintonizaron por el cervantismo. Tal como lo conozco. De Anales Cervantinos, de D. Francisco Maldonado y del equipo de redactores con D. Alberto, D. José Ares, etc., remito a mi trabajo en Actas del Coloquio internacional indicado en la nota, titulado «La empresa romántica de la Asociación de Cervantistas» ${ }^{1}$. En él cuento como conocí a José María en 1976. Ha sido por la pregunta de Abraham Madroñal como ha surgido el cuándo se conocieron D. Alberto y José María. Me he valido de mis contactos del ayer en el caserón entrañable de Duque de Medinaceli 4, luego el número 6.

José María apareció por la biblioteca del entonces Instituto «Miguel de Cervantes» iniciados los años setenta. La biblioteca, en el segundo piso, tenía un ámbito reducido y el contacto era muy directo entre el personal bibliotecario y los lectores. Un día - no venía con frecuencia José María - hablando con Sonsoles Arangüena, bibliotecaria desde hacía ya diez años al sustituir a Angelita Montoya (entonces en el «Jerónimo Zurita»), le preguntó por D. Alberto, a quien no conocía personalmente y sí por su labor y publicaciones en Anales Cervantinos. Sonsoles le informó de que venía por el Instituto a trabajar y de que era una persona muy asequible. Sonsoles, finalmente, presentó a José María a D. Alberto. Fue asimismo Sonsoles quien años después nos puso en contacto a Juan M. ${ }^{a}$ Díez Taboada y a mí con José María. El motivo fue la convocatoria del congreso internacional cervantino de 1978, dirigido por Manuel Criado de Val. La Asociación de Cervantistas se fundó

1. Con los pies en la tierra. Don Quijote en su marco geográfico e histórico. Homenaje a José María Casasayas (2005), edición a cargo de Felipe B. Pedraza Jiménez y Rafael González Cañal, Cuenca, Universidad de Castilla-La Mancha, Serie Homenajes n. ${ }^{\circ} 11.2007,566$ pp. El artículo citado en pp. 53-68. 
en 1988, y D. Alberto fue primer presidente (1988-1996) junto a Casasayas como vicepresidente. Todo esto lo relato en el artículo citado. José M. ${ }^{a}$ había dejado su actividad empresarial y jurídica en Palma para fundar la Asociación con la ayuda de los profesores e investigadores a los que fue conociendo. Y distinguió entre su afición bibliofílica y su pasión bibliográfica cervantina. Esta nunca la dejó, junto a su empeño en verter al mallorquín Don Quijote de la Mancha: Don Quixot de la Manxa².

\section{LA CORRESPONDENCIA (I976-I978)}

La componen 18 cartas, cada una de las cuales va encabezada por un breve resumen. Primero las de José María y después la respuesta de D. Alberto, que no siempre la hubo. En esta primera entrega ofrecemos las siete primeras cartas (31-I-1976 hasta 28-V-1976) con sus correspondientes contestaciones. Las once restantes quedan, pues, para el siguiente volumen de la revista.

\section{Carta primera: $31-1-1976$}

José M. ${ }^{\mathrm{a}}$ enumera los diez apartados para resumir la idea que tuvo todo su pensamiento posterior: la bibliografía cervantina, a la que consideró «empresa». Le llama entonces Archivo Bibliográfico Cervantino y lo defiende como amalgama entre el pensamiento del mismo Cervantes y su desarrollo en el mundo empresarial moderno. Una utopía esencial en su pensamiento.

Sr. D. Alberto Sánchez

Alcalá 323

Madrid

Mi muy estimado amigo:

Animado por la extraordinaria y afectuosísima acogida que Vd me dispensó, voy a intentar, por medio de esta que presumo larga carta, continuar y acabar de puntualizar el tema que le expuse. Será, todavía, a grandes rasgos aún; aunque me seduce tanto la idea que tengo en mi mente y en mis notas infinitos detalles, a mi modo de ver ya resueltos. Pero estos vendrán más tarde, si creemos que conviene seguir adelante.

Abusaré del tiempo y de la paciencia de Vd, pero tendrá que convenir conmigo en que sólo su acertada labor en pro del auténtico cervantinismo tiene la culpa. Así que paciencia, y barajar. 
Tengo que expresarle mi opinión, antes que nada, acerca de la posibilidad de una (¿otra más?) sociedad cervantina.

No soy partidario de las sociedades de ningún tipo «legalizadas» más que cuando se trata de las anónimas. Hay que ser crudo y realista si queremos que una empresa integrada por varios socios nazca con posibilidades de viabilidad. Ya quijotizaremos en otros momentos. El hombre nunca se siente verdaderamente unido a sus semejantes más que cuando presiente ser objeto de agresión por parte de terceros: sólo entonces, y para conservar la esperanza respecto a su subsistencia, decide agruparse con los demás, y crea así una familia, los clanes, la patria incluso. Una sociedad anónima no es más que el reflejo de esta postura (así expuesta acaso un tanto primitivista, lo reconozco) para subsistir en el mundo mercantil moderno, que es una de las formas de hacer o soportar la guerra. Y aún así, a pesar de la aparente unión de sus miembros, ello no impide que el socio A sea enemigo personal del socio B.

Vengo a decir con ello que opino muy de veras que una sociedad normalizada, con sus reglas, sus estatutos, etc., que sea eso que pretendemos, puramente cervantina («amigos de Cervantes», pongo por caso), está de antemano condenada al fracaso como tal sociedad o comunidad reglada. Ello no es óbice, no obstante, para que los que sentimos una cierta predilección por el fenómeno cervantesco no nos sintamos también unidos, hermanados entre sí, en defensa de una causa común, y aún a pesar de las previsibles rencillas propias, según el ejemplo dado, de una sociedad mercantil.

La sociedad cervantina auténtica, sin bastardilla, debemos formarla, pues, casi inconscientemente, todos los que sentimos necesidad vital de defender nuestras aspiraciones o ideales; los cuales, aunque en su forma o en su interpretación puedan parecer dispares, siempre tendrán de común la vinculación, la querencia hacia el desciframiento (y Dios quiera que no llegue nunca) de la incógnita que supo legarnos Cervantes.

Una sociedad cervantina que promueva discursos, que coloque medallas o nombre caballeros andantes a sus socios, o que se sirva del nombre de don Quijote para lanzar productos de consumo al mercado (en Palma tenemos una lavandería con el título de «La Mancha de Don Quijote»), ni me va ni me viene. Como partidario del más amplio espíritu liberal en todo orden de cosas, debo tolerar que los demás tengan sus propias ideas, aunque yo no comulgue con ellas. Pienso, en definitiva, que hasta el número infinito de necios, según ya recordaba Cervantes, no hace más que ayudar a la pervivencia de nuestro héroe.

Confío en que así como me expreso se me entiende también. Huyamos de las normativas que son producto del artificio; y que, además, aplicadas a una causa común la mayor parte de las veces son pruebas sintomáticas de su decadencia. No es casual el hecho de que la proliferación y subsiguiente codificación de las leyes de Roma coincidiera con el inicio de su ocaso. Y pretendamos, en definitiva, y porque ello implica quizás la necesidad de vivir quijotizando, alguna empresa más seria y definitiva. 
II.

«Empresa» en doble sentido: de un lado, tal y como pudiera interpretarlo el mismo Cervantes (¿no es hazaña quijotesca la de los astronautas?); y del otro, tal y como pueda concebirse en el mundo empresarial moderno (¿no resulta ejemplar la perfecta organización de los vuelos espaciales?). Resulta imposible, en cualquier momento, intentar evadirse de estos dos mundos. Cervantes nos lo demostró.

Sea como sea, y ya sin más divagaciones, mi proyecto se propone la formación de un Archivo Bibliográfico Cervantino, con propósitos que se deducen de su mismo enunciado. Algo así, pero con más ambiciones universales, de lo que está Vd haciendo en la sección de bibliografía de los Anales Cervantinos. Es decir: tendente a la exhaustividad.

A ver si soy capaz de esbozarlo siquiera, de intentarlo por lo menos. Luego, quizás, ya Dios dirá, que está siempre callado, según cantó el poeta.

III.

Este Archivo Bibliográfico Cervantino debería proponerse dar al mundo lo siguiente:

$\left.1 .^{\circ}\right)$ Un catálogo completo de todo lo publicado referente a Cervantes, por partida triple, a saber:

a) Catálogo por estricto orden cronológico (obras de Cervantes, miscelánea, obras sueltas, artículos, imitaciones, etc. etc.).

b) Id. id. por estricto orden alfabético de autores de las obras (las mismas obras de Cervantes pueden relegarse para el segundo de los catálogos, pero no pueden omitirse los comentadores, prologuistas, anotadores, etc.).

c) Id. id. temático. Desde luego el de más difícil composición, dada su complejidad y que requiere criterio científico, firme y único de sistematización desde su primer paso.

Entiendo, ya entrando sólo en los principales detalles, que tiene que llevarse a cabo en forma de fichas independientes, sueltas, que si bien es más costoso, a primera vista, que en forma de libro, a la larga contiene muchas más ventajas: 1) se puede empezar a distribuir a partir de las primeras fichas impresas, sin esperar la terminación de todo lo catalogable, que llevará años, sin duda; 2) admite la interpolación de números, descubiertos con retraso; 3 ) y la enmienda de errores, de imprenta o de concepto; 4) permite la suscripción independiente a cualquiera de las tres secciones mencionadas: 5) y aún dejaría en libertad para que cada cual se ordenase, por ejemplo, el temático, a su gusto y manera; etc.

Cada ficha debería contener: 1) descripción bibliográfica de la obra objeto de la ficha, pero no con la minuciosidad que creo imprescindible para el catálogo reservado a obras de Cervantes y que diré luego; 2) resumen, a ser posible escueto pero lo más orientativo posible, del contenido de la obra, y mención del colaborador que ha proporcionado el dato y hecho este resumen; 3) mención de sucesivas ediciones de la misma obra; 4) en caso de obras de gran rareza, mención de su localización en bibliotecas; 5) siglas, abreviatura, etc., con que esta obra debe ser citada siempre (para 
lo cual debería establecerse previamente un criterio uniforme); 6) un número para mejor localización de una ficha que debiera ser sustituida por otra más completa.

El fichero debería abarcarlo todo. O por lo menos aspirar a ello. Incluso la simple poesía «A Cervantes», "Al genio», etc., de los concursos escolares. Nadie puede predecir lo que, con el tiempo, llegará a tener interés permanente.

En cuanto al orden de aparición del fichero debería procurarse en sentido doble: De una parte, ir catalogando todo lo coetáneo, a fin de mantener al cliente (he dicho «cliente» a sabiendas de que empleo un término puramente comercial; no puedo evadirme nunca de la circunstancia de vivir en el siglo XX) al día en todo lo relativo a Cervantes. Y de otra parte, catalogar con carácter retrospectivo todo lo que se haya publicado al respecto.

Papel, cartulina, tamaño, tipo de letra, etc., etc., y demás infinitos detalles, son cosas que ya se resolverían en su momento. No adelantemos demasiado.

$\left.2^{\circ}{ }^{\circ}\right)$ Un catálogo completo de todas las obras de Cervantes. En realidad debería ser una parte integrante de la sección alfabética, pero dado su peculiar interés, creo necesario separarlo del resto. Cada ficha debería contener los mismos datos que los expuestos para el catálogo general, pero la descripción bibliográfica hecha aquí lo más minuciosa posible. El mejor ejemplo que conozco es el catálogo de Arents sobre las obras de Cervantes en los Países Bajos, y aún podría mejorarse el sistema.

3. ${ }^{\circ}$ ) La edición de un Boletín del Archivo, de aparición bimestral o trimestral, pero no más claro, a fin de ofrecer a los interesados las siguientes secciones:

a) Las actividades del Archivo (normas generales de catalogación, fichas emitidas, adiciones, enmiendas, noticias, etc.).

b) Artículos monográficos sobre bibliografía cervantina (Por ejemplo: las ediciones cervantinas de tal editor, noticias sobre bibliotecas cervantinas, historia de alguna edición especial, etc.).

c) Reseñas de obras bibliográficas cervantinas.

d) Noticias de carácter general (congresos, próximas obras, etc.) de referencia cervantina.

e) Podría contener también, una vez al año, la dirección de los colaboradores a fin de que pudieran ponerse en contacto entre sí. (Es de gran utilidad: creo que la idea fue lanzada por alguna sociedad ornitológica británica, y luego imitada por otras, y personalmente he podido comprobar los buenos resultados que ello proporciona).

4. ${ }^{\circ}$ ) Aparte, y según fuera aconsejable, podría crearse una sección, con su correspondiente medio de comunicación al público, que, saliéndose un tanto de lo estrictamente bibliográfico, abarcarse el estudio de las repercusiones de la obra de Cervantes en el arte en general y que se escapan del campo exclusivo del Archivo. Me refiero, por ejemplo, a la música, la pintura, la escultura, la cerámica, etc. Pero considero que esto, de momento, debe quedar al margen de la finalidad propia del Archivo. 
IV.

Pues, insisto en ello, opino que por ahora débese constreñir el proyecto a lo estrictamente bibliográfico. Por varias razones:

1. ${ }^{\text {a }}$ Voluntad consciente de que hay que autolimitarse. No es posible abarcarlo todo.

2. ${ }^{a}$ Sólo es posible perfeccionar una obra si de antemano se sabe que es perfeccionable. El campo de la bibliografía admite esta posibilidad. El campo de la especulación científica, cultural, etc., no la admite. Dejemos que otras publicaciones, otras instituciones sigan investigando en torno a Cervantes, y demos nosotros sólo el resultado de estas investigaciones.

3. ${ }^{\mathrm{a}}$ La bibliografía tiene unos confines bien definidos y, si se quiere, no hay posibilidad de que se salga uno de ellos.

4. ${ }^{a}$ Constituiría la manifestación más elocuente, el más claro monumento, etc., en honor a Cervantes. (Aunque personalmente detesto los homenajes).

V.

La tarea es inmensa, ya puede $\mathrm{Vd}$ suponerlo mejor que yo, y requiere para irla llevando a cabo (y más aún para rematarla) nada menos que colaboradores capacitados, tiempo y dinero.

Desecho, por descontado, la idea de una empresa individual, en base a su propia imposibilidad física intrínseca.

Cuando pienso en dejar la empresa en manos de una institución docente, cultural, etc., y asocio tal idea con un organismo oficial, del Estado, el desánimo se apodera de mí al contemplar la larga tradición española mantenida por las asociaciones estatales en orden a su falta de recursos, a su lentitud, a su inseguridad, a su relego en segundo término para dejar paso a otros fines menos culturales, etc. Si el funcionamiento y el mantenimiento de la empresa tiene que depender de algún organismo oficial, el tiempo se cuidará de demostrar que, habiendo sido un buen proyecto, no se han obtenido más que pobres resultados. Puede aceptarse, cómo no, y venga de donde viniere, cualquier ayuda moral o económica; pero debe ser rechazado todo intento de control oficial.

Tenemos, pues, que limitarnos a esperar la ayuda económica de alguna fundación, de particulares, de bancos, de quien fuere en definitiva, que tenga interés en ello, y acaso que cuente con que toda la ayuda que nos preste serviría también para su desgravación fiscal.

Pues una cosa es cierta, ciertísima: que los ingresos por suscripciones $o$ anuncios comerciales en el boletín no van a cubrir ni una pequeña parte de los gastos necesarios.

Es imprescindible esta ayuda económica. Pero lo es más aún el saber cuál tiene que ser el modus operandi abstracción hecha de toda cuestión financiera. Sin un previo esbozo de la infraestructura (¿no se dice así ahora?) de la organización, no se puede entrar en el capítulo de súplica y peticiones de dinero. 
VI.

Este modus operandi lo presumo eficaz únicamente a base de colaboradores eficientes esparcidos por todo el mundo que vayan enviando papeletas al centro del Archivo: de forma ordenada y sistemática por lo que toca a todo lo actual, y según se pueda por lo que toca a la parte retrospectiva.

Como es lógico, previamente se establecerían unas directrices de cómo hay que confeccionar las papeletas, a fin de obtener uniformidad al presentarlas a los interesados. Aunque cada colaborador (se admitirían incluso los eventuales espontáneos) tuviese su propio campo de acción, escogido ad libitum, la duplicidad de papeletas lejos de ser un inconveniente sería una ventaja al permitir la selección de las más acertadas.

Y como es evidente que la empresa en un plan económico no sería rentable, a fin de eliminar gastos, debería procurarse que estos colaboradores no viesen compensados sus esfuerzos más que con la propia satisfacción moral de haber coadyuvado en una obra útil y, quizás, con la recepción gratuita del fichero y del boletín. Pero, ¿es posible conseguir semejante colaboración gratuita? ¿Ni aún el cervantista puede sentirse por unos momentos imitador de verdad del espíritu que animaba a Don Quijote? Desconfío mucho de la generosidad ajena, aunque sea para un fin noble; pero ha de salir uno al campo y probarlo. O colgarse de un pino, al decir de Rubén Darío.

VII.

Tengo vagas ideas, lo confieso, acerca de cómo el centro del Archivo (receptor, coordinador, elaborador e impresor de las papeletas, y organizador de la parte administrativa) deba componerse y deba actuar, aunque, desde luego, me lo imagino. Como imagino también que este centro debe estar compuesto de elementos científicos (en especial por lo que se refiere a la clasificación temática) y de elementos simplemente manuales. Ya se verá cuál sea el mejor sistema.

Pero sí que tengo, en cambio, idea clara de que sin una biblioteca cervantina, en especial por lo que se refiere a bibliografía, no se iría a ninguna parte. Es muy posible que mi desmedida afición a los libros exagere la idea de esta necesidad.

Sea lo que fuere, lo creo un capítulo importante: y más si se tiene en cuenta que no es poco costosa una biblioteca. Espero que con el intercambio de revistas puedan conseguirse las innumerables publicaciones periódicas sobre temas literarios que siempre suelen llevar, como es natural, alguno/s artículo/s sobre Cervantes. Y de todas formas, si este proyecto llega a convertirse en realidad, yo ofrezco la aportación completamente desinteresada de mi biblioteca, que si bien me parece incipiente cuenta ya con más de 1.200 obras de Cervantes, unas 1.500 de exclusiva miscelánea cervantina, y alrededor de los 5.000 artículos ídem esparcidos en revistas y publicaciones.

\section{VIII.}

Se impone una consideración de tipo moral. Esta empresa, de llevarse a cabo, debe enorgullecer a todos pero no engreír a nadie en particular. Que ninguno de los que participen en ella se sienta con derecho a prerrogativa 
especial alguna, ni siquiera a la de que su nombre se escriba con letras de moldes diferentes a las de los demás. Un coleccionista, cuyo nombre siento no recordar ahora, donó su biblioteca a cierta institución con la condición expresa de que en sus salones no podía figurar imagen, busto o nombre alguno que no fuera el de Cervantes o de alguno de los personajes de sus obras. Este riguroso principio debe presidir, como síntoma del espíritu de colaboración, nuestra organización.

IX.

Me pregunto, y se lo pregunto a $\mathrm{Vd}$ directamente con la súplica y la esperanza de obtener una franca contestación: ¿no habré incurrido, con la imaginación de este proyecto, en el mismo error — práctico, cabe puntualizar - en que incurriera nuestro universal héroe manchego al proponerse arreglar el mundo por medio de un caballero andante al frente de las tropas del emperador? «Tanto me da el soñar, que a fin de cuentas / al despertar en sueño me convierto», según un olvidado poeta sudamericano dijo. Que mi idea sea hermosa y atractiva, nadie va a contradecírmelo. Que sea factible, ya es harina de otro costal. Me conformaría de momento en que fuera «estudiable».

Y si lo es (y aquí el parecer de Vd tiene para mí una importancia decisiva), sugiero, más bien en mi fuero interno requiero, una reunión de trabajo de especialistas en la materia ( $\mathrm{Vd}$ y los que $\mathrm{Vd}$ conozca, que yo no sé de nadie más que por puras referencias bibliográficas), los más significativos, a fin de estudiar conjuntamente, primero la viabilidad de este proyecto, y, segundo, si así se establece, todos los demás puntos precisos para ponerlo en marcha.

Propongo, a tal fin, como lugar Mallorca y como época mayo: en total, conjunción de primavera mallorquina, que suele ser, por regla general, espléndida. Posiblemente pueda conseguir alojamiento pagado por unos cuantos días en hotel de primera clase, pero la verdad es que, personalmente y ahora por ahora, no puedo empeñar palabra. Con mucho gusto atendería yo mismo a estos gastos iniciales, que no iban a ser muchos, pero la situación financiera en general (y yo no soy una excepción) está tan descalabrada que para ello tengo yo que esperar mejores tiempos.

Lo que sí casi puedo aventurar es que si de esta reunión resultara, como es de esperar, algo positivamente optimista, se obtendría una ayuda económica necesaria para organizar con mayores formalidades un Congreso Internacional de Cervantistas.

Hay que proponérselo, amigo Sánchez.

$\mathrm{X}$.

Le he escrito, como puede Vd darse cuenta, a vuela pluma y sin más concatenación de ideas que lo que podría esperarse de quien, metido en un odiado mundillo mercantil (con sus altibajos, sus guerrillas económicas, la escasez de dinero las más de las veces, y los golpes bajos siempre), se ha pasado casi cuarenta años de su vida anhelando la superación de lo material por medio de este espejismo mágico que, como un milagro, nos legó el genio de Cervantes. Creo que vivir sin un ideal, sea cual fuere, no vale la pena. No quiero establecer comparaciones sobre si es mejor una aspiración del 
orden de la que tengo u otra cualquiera, aunque sea ésta la de ir acumulando monedas de valor corriente. Pero sí espero que, por lo menos, el esfuerzo en pro de una causa que considero tan desinteresada me disculpe de mis apresuramientos y de mis yerros.

Aparte ya: ¿puede mandarme la colección completa de la revista que publica el instituto de Vd? Contra reembolso es el mejor sistema, pero si Vd lo prefiere se lo adelantaré por medio de cheque.

Otro día, si no le molesta a Vd, me interesaré por direcciones de algunas editoriales extranjeras que podrán ofrecerme algunas obras que me interesan.

Y, se lo ruego, contésteme dándome su opinión a todo lo que le he expuesto.

Afmo.

José M. ${ }^{\text {a }}$ Casasayas

[Nota manuscrita] Lleva ya días escrita esta carta. Hoy, 7-II-76, me decido enviársela sin enmendar nada de su espontánea redacción.

\section{Contestación de 15 de febrero de 1976}

D. Alberto se muestra precavido con los proyectos de José María por la experiencia en el pasado. Recuerda, por ejemplo, el centenario que se vivió en 1947 y de cuyo proyecto editorial bien poco se materializó, si bien de mucho interés. Habla de la posibilidad de un primer Congreso Internacional de Cervantistas.

Madrid, 15 de febrero 1976

Sr. D. José M. ${ }^{a}$ Casasayas Truyols

Palma de Mallorca

Querido amigo:

Hace pocos días recibí su estimable carta del 31 de enero, remitida el 7 del actual, y la he leído atentamente en sus X apartados.

Por supuesto, las ideas esbozadas son altamente generosas y plausibles, pero en los términos que van expuestas las veo de muy difícil realización, por la falta de constancia y de trabajo en equipo entre los españoles, e incluso la indiferencia de nuestros medios financieros - en general- para estimular y sostener indefinidamente una fundación cultural de carácter tan especializado. La verdad es que si Alemania, Inglaterra, los Estados Unidos, o la misma Francia, tuvieran una figura de la categoría de Cervantes, una sociedad privada con su nombre, y publicaciones de la orientación que usted señala, contarían ya con un siglo de existencia: los nombres de Kant, Goethe, Shakespeare o Montaigne son buenos ejemplos. Pero yo, que ya voy peinando canas, recuerdo que la Asamblea Cervantina, reunida en 
1947-48, por iniciativa oficial, tomó una serie de brillantes acuerdos, algunos incluso pagando por anticipado a quienes se comprometieron a realizar determinadas ediciones cervantinas, que no llegaron a imprimirse: «gone with the wind», diremos con el título de la novela y película norteamericana. $\mathrm{O}$ «pasaron como verduras de la eras...» según el poeta español.

De ponerse en marcha algo así, crea usted que lo que menos habría de preocupar es cualquiera gratificación a los colaboradores. Somos muchos los cervantistas que colaboramos en Homenajes a profesores y revistas -escolares y universitarias, sin otra remuneración que recibir 25 o 50 separatas de nuestras aportaciones, para intercambiar con otros colegas. Mi Bibliografia y trabajos directivos en El Ingenioso Hidalgo y en Anales reciben la misma compensación, porque no puede llamarse retribución, o algo así, las humildísimas gratificaciones que alguna vez al año puedan recibirse, desde luego sin regularidad alguna.

Creo que la convocatoria, por alguna autoridad académica de reconocido prestigio internacional, para un I Congreso Internacional de Cervantistas, en Madrid o Barcelona, ciudades con acopio de más libros cervantinos en España, podría ser el vehículo inicial de la magna empresa que tan noblemente inquieta a usted.

Lo de esa reunión previa en Palma de Mallorca parece excelente, pero conviene tener en cuenta que el mes de mayo es el peor del año para los que nos dedicamos a la docencia. Por eso verá usted que, por ejemplo, los congresos de la Asociación Internacional de Hispanistas, cuya oficina está en Nueva York, y que se ha venido reuniendo cada tres años, en Oxford, Nimega, Méjico, Salamanca y Burdeos, siempre lo hace en julio, agosto o septiembre... Siempre se habla de Cervantes, pero no como tema único, por las diferentes especialidades de los asistentes.

En cuanto a su petición de la colección de la revista de este Instituto, la he cursado al director del Centro, Dr. D. Antonio Mingarro, que es el que dispone todo lo referente a la distribución y administración de El Ingenioso Hidalgo. Tiene ya la tarjeta de $\mathrm{Vd}$. con la dirección para hacer el envío. Prefiere el pago por cheque al reembolso; pero lo mejor es que le escribiera usted sobre este aspecto.

No creo que mi carta pueda desanimarle, por cuanto me he limitado a exponer las primeras sugerencias, en vista de proyectos anteriores malogrados. Después de todo, el quijotismo es energético y voluntarista, inasequible al desaliento. Claro que Don Quijote era caballero solitario. Sancho le acompaña «desde fuera».

Siempre a su disposición en Cervantes, le envía un cordial saludo.

Alberto S S/C: Alcalá, 323 MADRID-27 


\section{Carta segunda: 8-III-1976}

Contiene la opinión de Casasayas a la carta de D. Alberto. Se muestra escéptico con las ayudas oficiales. Se desprende por dónde D. Alberto fue interesando a José María en conocer a los estudiosos del cervantismo internacional, pues a este, como señor particular en Palma de Mallorca, le resultaba difícil. Precisamente hay correspondencia muy interesante de los profesores italianos Franco Meregalli y Donatella Moro (con don Alberto).

Sr. D. Alberto Sánchez

Palma de Mallorca, 8 de marzo 1976.

Alcalá, 323

Madrid - 27

Mi estimado amigo:

Con suma atención leí su apreciable carta, que un poco de gripe, un más de trabajo y una mayor asimilación, a lo que espero, de la sana prudencia que $\mathrm{Vd}$ rezuma por todos los costados, han retrasado más de lo debido. (Aclaro a guisa de inciso: Si tuviésemos que imitar a Don Quijote y seguir a Unamuno el concepto de prudencia no sería calificado nunca de sano. Ni Colón hubiera ido a América.)

Me alegro de que esté conmigo en que toda ayuda oficial en una empresa semejante a la que me bulle en la imaginación es vana. Yo añado más: que no solo es vana, sino perjudicial, por entorpecedora. Podríamos citar mil ejemplos, que Vd conocerá mejor que yo. Sé más o menos de referencias la historia del pretendido homenaje perenne a Cervantes, suscitado a raíz del III Centenario de su muerte muy levemente y con más ímpetu en el IV de su nacimiento. "Arrencada de cavall i parada d'ase», como decimos en mallorquín. Creo sinceramente que la empresa estatal no es apta más que para demostrar esa diarrea legislativa que la está caractizando. Leyes, decretos, órdenes..., que si por una parte denotan un nerviosismo propio del que quiere pero no puede acertar, por la otra hacen que el «hecha la ley hecha la trampa» se haga imperiosa necesidad del vivir cotidiano. ¿Se ha propuesto alguien estudiar las consecuencias que acarrearía el comportarse con estricta sujeción a la normativa vigente?

Experimentalmente he tenido ocasión de comprobar esta imposibilidad de todo organismo oficial. Hace ya unos quince años, un prudente y fanático (si es posible conjugar los dos principios, en este sujeto se daban) se propuso organizar en Palma los mejores internacionales (mejores en todo el mundo) torneos de ajedrez. Tenga usted en cuenta que el ajedrecista es aún más vedette que las tiples de ópera y más exigente que un erudito cualquiera. El costo de cada torneo oscilaba entre los 3 y 4 millones. Yo formé parte, como segundo jefe digamos, de todos estos torneos. Mire si estaba peliaguda la situación (nos hallamos en 195...) que hablar de que un ruso (¡de la Rusia comunista!) viniera a España era ganarse el anathema sit oficial. Se habló con la federación, que quiso alzarse en organizadora; se insistió en todos los ministerios posibles; etc., etc., para no alargar. Al 
final, la cosa se hizo, pero con una mínima ayuda oficial (el Ayuntamiento, la Diputación, la Federación, etc., contribuían con ridículas cantidades) y, desde luego, apartando de la organización a cualquier quisque que oliera simplemente a personaje administrativo. ¿Querrá Vd creer que algunos de los trofeos ofrecidos - y como tal anunciados - por organismos y autoridades tuvimos que pagarlos nosotros mismos? Esto se hizo durante siete $\mathrm{u}$ ocho años. Y fueron los mejores torneos del año, en todo el mundo, cada vez. Más aún: de estos torneos de ajedrez nació la idea (la tuvo un catalán, director, pero no el organizador financiero, de los torneos) de una cooperación de periodistas y publicistas internacional de ajedrez que, luego acogió la FIDE en su seno, y que cada año otorgan el Óscar mundial al mejor jugador, y que, con organización que ahora reside en Yugoslavia, están recopilando todo, absolutamente todo, lo que ha publicado sobre ajedrez, todas las partidas, etc. Algo así como yo pensaba que podía hacerse con lo de Cervantes.

¿Por qué, pues, sí, en un plano casi igual, se está haciendo, no puede hacerse con Cervantes?

Bien está que los aspectos interpretativos, las glosas a los textos, etc., sean obra de genios eruditos individualmente sitos en el complejo mundo de la investigación. Al fin y al cabo la obra cervantina da pábulo a todo lo que sobre ella se ha escrito, y a mucho más aún. Pues veremos qué nuevas interpretaciones, qué nuevos matices se le van encontrando, ahora no vistos, a los personajes y a las situaciones de Cervantes. Pero el simple hecho material de querer agrupar la historia de esta ramificación espesa a lo largo de toda la historia literaria es algo más que exclusivo del esfuerzo de uno. Con mucho gusto (y, desde luego, pienso hacerlo a partir del año próximo en que, según calculo, acabaré de tener bibliografiado sólo lo que tengo en casa) destinaría tres o cuatro meses al año a hurgar en los principales centros cervantinos de todo el mundo (en mente ya me los sé todos) para ir acopiando datos. Pero, ¿qué es ello junto a lo que es preciso hacer?

Vd. y yo solos, no haríamos más que empezar. Vd., y yo, y dos más, por ejemplo, ídem de ídem: empezar multiplicado por dos. Y aún así, ¿qué? Sin embargo, yo no estoy tan desalentado como Vd. en que esperar la ayuda de los demás sea una utopía. Dada la cantidad de cervantistas que hay por el mundo (y el cervantismo, como Vd. apunta, lleva consigo intrínseco el entusiasmo), me atrevo a asegurar que si se les expone la idea, habrá pronto más colaboradores de los que en realidad se precisan. Unos, los más, irán luego desfalleciendo. Ya se sabe. Pero quedarán los que ultimarán la obra.

Pero, para hacer llegar esta idea, este proyecto, a todos, es decir, para lograr la máxima difusión, no se me ocurren más que dos caminos:

- uno que, partiendo del chispazo individual, lance una proclama al mundo entero por medio de volantes, anuncios o simples folletos impresos demandando ayuda. Pero, calcule Vd. sólo el coste de la impresión de estas proclamas y su envío por correo a los distintos centros o personas ad hoc y se acercará pronto a los dos millones de pesetas. Por lo que, más viable creo y veo

- el otro camino: o sea, el de un Congreso de cervantista, con tema dedicado exclusivamente a la bibliografía (estamos cansados de ver con- 
gresos de temas limitados), que pone, dada su fuerza difusoria, a todo el mundo erudito en alerta. Pero para este congreso es preciso un previo comité, a escala reservada, para tratar primero del tema en sí, y segundo de su organización. Este pequeño comité, que es lo que proponía en mi carta ( $\mathrm{y}$ al que no he renunciado todavía), no cuesta prácticamente nada: unas vacaciones de tres o cuatro días de unos cuantos individuos.

Y la cosa está en que para el primero de los proyectos, verdadera quijotada, no se va a encontrar a nadie que esté dispuesto generosamente a financiarlo (¿Por qué, Dios mío, no acertaré algún día una quiniela de 14 resultados y única?). Pero para el segundo (me refiero ya al Congreso), si en su exposición se cuenta con la firma de personas — eruditos, que también lo son, caramba - de categoría relevante, le aseguro a Vd. que si no aquí, por lo menos en Barcelona se encontrará la ayuda económica precisa.

$\mathrm{Si}$ otros lo han hecho, no menos que ellos podemos ser nosotros. Si Vd, está peinando canas, como dice, no menos acaso tenga yo. $\mathrm{Y}$ juraría que en cuanto a desengaños, pues ya estoy ahíto de ellos, no me gana Vd. ni nadie. Y, sin embargo, no pienso corregirme más que a la hora de la muerte, como el buen Alonso Quijano. ¿Se imagina Vd. que D. Quijote viviese aún una veintena de capítulos más después del reconocimiento de su locura al final de la segunda parte de su historia? No lo resistiría. Lo más probable es que abjurase de su cordura y acometiese una nueva salida, pero esta vez con el firme propósito de no volver a su aldea para no verse en el trance de tener que cantar por segunda vez la palinodia.

Hay otro tercer camino o vía para llegar a los fines propuestos: que una Universidad USA (Kansas, por ejemplo, que presume tener lo mayor, siempre) lleve a cabo la empresa. Y sí lo haría a poco que se lo propusiera. Pero, señor, me duele lastimeramente que el centro de esta operación se salga de España. Aunque a fin de cuentas si el resultado es óptimo, vengan de donde vinieren sus medios, loado sea el Altísimo.

Debo acabar porque de lo contrario hay peligro de que se repitan los seis o siete folios de mi carta anterior, y no quisiera causarle a $\mathrm{Vd}$. más tormento. Cuando me pongo a escribir sobre el tema, como he estado siempre tan asilado en este aspecto (sólo en este aspecto, pues por mi profesión de abogado - o res admirabilis: advocatus sed non damnatus, dice una oración a San Ivo - tengo que estar relacionado hasta con truhanes y pícaros, que abundan más de lo que uno quisiera), cuando me pongo a escribir, y lo hago sin pensar siquiera, ex abundantia cordis os locutur (y va otro latinazo). Mi esposa me incita de continuo a que escriba novelas, a ver si gana uno algún premio de estos que, no por el honor, sino el pecunio le sacan a uno de apuros durante una temporada. Pero yo ya tengo bastante con mis escritos al Juzgado, iy qué latosos!, y con preparar lo que tras «Y con la venia» tiene que decir uno para no quedar mal ante el aburrido oyente.

Seguiremos otro día, si no le molestan mis cartas. Por lo menos tolere Vd. que me explaye. Voy a tener la ilusión de que Vd. me sigue con atención, y eso, al decir de Pirandello, ya compensa.

Paso a dos ruegos que, aunque sobre lo mismo, se salen de lo ordinario:

1. ${ }^{\circ}$ He recibido estos días el último tomo de los Anales Cervantinos XIII-XIV, 74-75 (cada vez es más exigua la aportación) y leído con sumo 
interés el artículo de los Sres. Porqueras y Laurenti sobre los fondos de la colección de la Universidad de Illinois. ¿Podría Vd. hacerme el favor de hacer llegar al Sr. Porqueras, que ni siquiera sé si vive en Madrid, la carta que va adjunta? Puede leerla Vd. si gusta de ello, y se enterará del tema. Está escrita en plan de cooperación. Y si por parte del Sr. Porqueras cayese en saco roto, paciencia. Tampoco puedo yo pedir más.

2. ${ }^{\circ}$ Estoy bastante bien relacionado con libreros de varias partes del mundo, que, si lo pido, me van mandando cosas. Me refiero especialmente a Francia, Inglaterra, Alemania, y USA, y México también. Pero, créalo Vd., no he podido tener todavía ningún contacto con alguien de Italia, de donde me interesan ciertas obras (por ejemplo, el Quijote que Vd. tan bien comenta en su última bibliografía). ¿Sería Vd. tan amable de darme alguna dirección? Desde luego, no acostumbro a pedir nada gratis. Me falta también un enlace con la URSS y satélites. Tengo muy buenos amigos ajedrecistas, pero éstos, como las divas, repito, son antojadizos e inconstantes y no viven más que para lo suyo y la música. Es inútil pedirles otra cosa.

Ruego que comunique al Sr. Mingarro (a quien escribí el día $1 .^{\circ}$ de este mes) que he recibido los 44 números del EL INGENIOSO HIDALGO. Les estoy muy agradecido a Vds. por la diligencia desplegada.

Dígame algo, aunque sea poco. No sabe cuánto se lo voy a agradecer.

Casasayas

\section{Contestación del 28 de marzo de 1976}

D. Alberto defiende Anales Cervantinos, dado que José María no entiende cómo son los presupuestos de la administración oficial. Tal como se pensaba entonces que podía ser una asociación de carácter bibliográfico, D. Alberto comenta la posibilidad de exponer el proyecto en una próxima reunión de tema bibliográfico en la Fundación Universitaria Española.

Sr. D. José M. a Casasayas Truyols

Orfila, 6-bis

Palma de Mallorca

Mi querido amigo:

Recibí oportunamente su carta del 8 del mes en curso, a la que no he podido contestar antes por un largo viaje, realizado hace poco, y la aglomeración de tareas escolares en final de trimestre. Algo liberado ya de tareas atrasadas, y con la esperanza de una mayor liberación, a la vista de las próximas vacaciones de Semana Santa, que pienso pasar en mi pueblo de Cheste (Valencia), libre de la contaminación atmosférica de la gran ciudad, me dispongo a contestar a sus preguntas. 
Deja caer usted, al pasar, en su carta última, que cada vez es «más exigua» la aportación de los Anales, con referencia ahora al tomo doble $\mathrm{XIII}+\mathrm{XIV}$, y debo contestar, pues me siento un poco responsable en mi calidad de Subdirector. Lo cierto es que, tanto la doble numeración del volumen - por primera vez empleada en esta publicación- como la reducción en el número de páginas, han sido impuestas a la redacción de la revista por la administración, que funciona como una superestructura independiente y dominante. Los criterios económicos funcionan como algo misterioso. Con decirle que incluso se vio amenazada la misma existencia de esta publicación, que es una de las que se agotan, entre las más especializadas de este organismo. Por ventura, parece que se ha conjurado, de momento, el peligro.

Alberto Porqueras, catalán de Lérida y buen amigo mío, desde hace años, está de profesor en la Universidad de Illinois. Casualmente, el día antes de recibir yo la carta de Vd., me visitó en el Consejo, de paso para una reunión profesoral en Centroeuropa, desde donde volvía a los USA, sin pasar por España. Pero vuelve el próximo mes de junio, a un Congreso sobre Novela Picaresca, al que yo presento una comunicación. Nos hemos despedido hasta entonces; pero la documentada carta de usted, sobre las precisiones bibliográficas a su trabajo en Anales, ya se la di a Luciano García, secretario de la revista, para que la remitiera directamente a la Universidad de Illinois, donde, seguramente a estas horas, ya la habrá leído Porqueras. Luciano García conoce, también por mi mediación, su ambiciosa empresa del fichero o archivo bibliográfico cervantino y nos ayudará eficazmente en el empeño.

En esta misma fecha anuncio otra comunicación mía en la Fundación Universitaria Española (privada, con domicilio en Madrid-9, c/ Alcalá, 93) para una reunión sobre temas bibliográficos en general, que se ha de celebrar en sus propios salones, durante los días 24, 25 y 26 de mayo próximos. La convocatoria la firma el gran bibliógrafo José Simón Díaz y asistirán, entre otros, Pedro Sáinz Rodríguez, Justo García Morales (encargado en la B. Nacional de la Sección Cervantina), etc. Mi trabajo, por supuesto, se ocupa de «algunas consideraciones actuales en torno a la bibliografía cervantina». ¿Me autoriza a presentar su proyecto de archivo, entre otras «consideraciones»? ¿Quiere que proponga a Simón Díaz el que sea usted mismo invitado personalmente para exponerlo? Creo que sería un buen momento, por la calidad de los asistentes, para lanzar el primer globo sonda... Como verá, las ocasiones salen al paso.

En espera de sus siempre gratas noticias, le envía muy cordiales saludos.

Alberto Sánchez 


\section{Carta tercera: 3-IV-1976}

Más comentarios sobre la carta recibida días antes. Vuelve a salir Anales Cervantinos y la aceptación de las ideas aportadas por Luciano García Lorenzo. También le parece bien que D. Alberto exponga la «empresa» bibliográfica, por lo que sale a relucir la reunión que se celebrará en Madrid en la Fundación Universitaria Española.

Sr. D. Alberto Sánchez

Palma de Mallorca, 3 de abril 1976.

Alcalá, 323

Madrid - 27

Mi querido amigo:

Con el firme propósito, que procuraré no transgredir, de no sobrepasar, en esta ocasión, el folio, contesto a la suya del 26 de marzo, que recibí tres días ha.

${ }^{1}$ No fue por malicia intencionada, sino por espontánea sinceridad, que califiqué de «exigua» (por lo corta, que no por su calidad) la aportación del último número, doble (?), de los Anales Cervantinos. La respuesta de Vd. ha venido a confirmarme lo que, desde un principio, le estoy exponiendo: que en cualquier empresa en que el organismo oficial, o para-oficial, mete sus narices, para expresarnos como Cela, no sólo se deja de alentar a los particulares colaboradores, sino que se les desalienta con las infinitas trabas, unas administrativas, otras financieras y otras misteriosas, como ocurre con los Anales. Y puesto en su lugar, comprendo perfectamente la pena que debe causarle a $\mathrm{Vd}$. mismo el hecho de que, aún desempeñando un alto cargo directivo dentro de la organización de la revista, se vea limitado, sin razones por lo menos aparentes, a, como quien dice, cumplir con los trámites.

Bien. No hay que desmayar nunca. Y si ocurre algún desmayo, cómo no, hay que levantarse con más bríos.

${ }^{2}$ Le estoy muy agradecido por el traslado de mi carta al Sr. Porqueras. $\mathrm{Y}$ espero contestación suya no puede $\mathrm{Vd}$. imaginarse con qué ilusión.

$\mathrm{Y}$ por la propaganda que hace $\mathrm{Vd}$. de mi proyecto. Salude a don Luciano García, a quien no tengo el gusto de conocer, en nombre mío. Y dígale, si viene el caso, que también aceptaré de él cualquier enmienda a mi locura bibliográfica cervantina. (He dicho «locura», pero realmente creo que más bien respiro «poesía». Siempre he estado convencido, y aún desde antes de leérselo a Leopardi, que los poetas son los únicos que en realidad transforman el mundo e infunden nueva vida a la humanidad; aunque sea de los que precisamente no se sirvan de versos rimados para ello).

${ }^{3}$ Y pasemos al último punto de su carta. Desde luego, y por descontado, y etc., etc., queda $\mathrm{Vd}$. total y absolutamente autorizado para exponer mi proyecto a quien, como y cuando Vd. guste. Y más aún si se trata de ello en una reunión de personalidades tan importantes como las que Vd. me dice que van a estar presentes en la Fundación Universitaria Española. Y voy a 
añadir que nada me haría en estos momentos tan feliz como el ser invitado a ella. Comprendo (y no lo digo por falsa modestia) que carezco de méritos suficientes para esperar tamaña deferencia. Pero, cielo santo, y cómo me gustaría. Le prometo desde ahora, si hace Vd. posible mi deseo, mi más eterno y profundo agradecimiento, aunque mi actuación se limitara a la simple asistencia como oyente. Que exponga el proyecto yo mismo o que lo exponga otro es indiferente. Creo que en una empresa de matiz cultural que beneficia a todos lo que menos debe importar es la vanagloria personal de uno; y en esto sí que le hablo con absoluta sinceridad. Jamás en la vida he tomado una sentencia favorable como un éxito propio, sino como un tributo obligado a la justicia. Los dos únicos inventos con categoría de tales que hoy atraen a la humanidad (y sigo con ello las paradojas de Chesterton), a saber, la rueda y la cucaña, son todavía obras anónimas.

Bien. Ya sabe. Se lo dejo todo confiado a Vd.

${ }^{4}$ Sigo metido en mi despacho como un ermitaño solitario. Algún día me voy a consumir de tanta soledad. Le he escrito casi a vuelta de correo para que llegue la carta antes de su partida para Cheste. (En mi infancia he pasado infinitas veces por Cheste; teníamos en el término de Requena, y junto al Cabriel, una finca, Casas del Río se llamaba, de casi 4.000 Ha., en donde íbamos todos los veranos. Luego mi padre la cambió por otra en Mallorca, de más fácil acceso para nosotros.) Pero no quisiera atosigarle con exigencias de respuestas rápidas. Ya está suficientemente atareado para, encima, perder demasiado tiempo en la literatura epistolar. A mí me viene ahora una semana de mucho trabajo en todos los sentidos. Luego, si Dios quiere y la mujer acompaña a ello, pienso irme unos días a Italia. Ya veremos. A lo mejor allí se me ocurre, a mí que soy tan soñador siempre, algún sistema para salvar Venecia en su hundimiento final.

Siempre agradecido, y en la espera de ir agradeciéndole aún más, quedo atto. y affmo.,

JMCasasayas

\section{Contestación del 25 de abril de 1976}

En una más extensa carta, le explica a José María cómo van a ser las jornadas bibliográficas, y la imposibilidad de que pueda intervenir como conferenciante. Además de recuerdos de un viaje por Italia, le comenta la actualidad de publicaciones cervantinas.

Madrid, 25 de abril 1976

Sr. D. José M. ${ }^{\text {a }}$ Casasayas

Palma de Mallorca

Querido amigo:

Oportunamente recibí su muy amable carta del 3 del presente mes, «puesto ya el pie en el estribo» para irme de vacaciones primaverales, que 
resultaron un tanto revueltas, a mi pueblo de Cheste. Reintegrado aquí desde el 20, voy poniendo en orden las muchas cosas que tengo pendientes, de cara a un final de curso, que se prevé más próximo de lo que podíamos haber supuesto.

Entre la correspondencia que me esperaba, figura una carta de Simón Díaz, fechada el 18, en respuesta a mi demanda de que fuera Vd invitado a las reuniones bibliográficas de la Fundación Universitaria Española, convocadas para los días 24-26 de mayo. Me comunica que ya no era posible cursar una nueva invitación por estar cerrado el cupo de participantes hace tiempo, cuya relación se me envía aparte, con un total de 38 , enumerados por orden alfabético y dando el título de sus ponencias, que afectan a distintos aspectos de la bibliografía española, incluidos libros raros y curiosos. De tema específicamente cervantino, solamente veo otra, aparte de la mía: la del Marqués de la Encomienda, acerca de «Cervantes en Bulgaria». El título de la que he de presentar yo, será «Algunas consideraciones actuales en torno a la bibliografía cervantina». Claro que la de Alberto Porqueras, «Libros españoles antiguos y raros en la Biblioteca de la Universidad de Illinois», es posible que contenga algunos datos interesantes para el cervantismo. Clausura estas tres jornadas bibliográficas D. Pedro Sáinz Rodríguez. De todas formas, copio textualmente lo que me dice Simón Díaz, organizador de ellas, al final de su carta:

«Por consiguiente, no es posible a estas horas efectuar ninguna nueva invitación, pero tampoco existe el menor inconveniente, dadas las razones expuestas, en que el $\mathrm{Sr}$. Casasayas asista a las reuniones, que en un principio pensamos fueran totalmente cerradas, pero que me presumo acabarán siendo todo lo contrario». Por otra parte, no se trata de una reunión exclusivamente de profesores universitarios o de Instituto, puesto que figuran en ella también bibliotecarios, coleccionistas y bibliófilos, descollantes por sus estudios en alguna faceta del tesoro bibliográfico o documental español. Como ha visto, Simón Díaz quiere que puedan asistir todos los interesados por la catalogación y organización del libro, aunque establece que ya no cabe cursar nuevas invitaciones, que llevan aparejadas el encargarse de una ponencia y tienen también su pequeña retribución, no de carácter oficial, sino de la misma Fundación Universitaria Española. Como demostración de la seriedad del caso, se nos indicaba que las ponencias se cobrarán al publicarse el volumen en que vayan recogidas.

Supongo que ya habrá regresado Vd. de su magníficamente proyectado viaje a Italia, y se habrá reintegrado a sus negocios y las tareas del foro. Recuerdo que, hace años, en uno de mis viajes a Italia estuve en Venecia dos días durante la Semana Santa y nos llovió bastante (y de tormenta, con muchos truenos, como esta semana última pasada en Cheste; pero en Venecia se notaba más, porque los vaporetti bailaban lo suyo, y todo era agua, arriba y abajo). De todas formas, San Marcos lucía como siempre y yo recordaba las palabras que le dedica Cervantes en el Licenciado Vidriera.

Amigo Casasayas: verá Vd. que esta vez le contesto en carta más demorada. Espero sus buenas noticias y, más aún, verle pronto otra vez por aquí, para seguir charlando de cuestiones cervantinas. Últimamente he recibido un estudio con el Buscapié de Adolfo de Castro y unos artículos norteamericanos acerca de los libros de caballerías; que, por cierto, se han 
puesto de moda en la Colección de Clásicos Castellanos, donde ya han aparecido una docena de tomos de ellos. Claro que, como son tan largos, bastan con dos títulos para dar esa cantidad de tomos.

Reciba muy cordiales saludos de su buen amigo.

Alberto Sánchez

\section{Carta cuarta: 29-IV-1976}

En tres apartados divide el tema de las reuniones a celebrar en Madrid, el tercero más personal, pero no menos interesante. En su pensamiento la «empresa» se llama Asociación Bibliográfica Cervantina.

Palma de Mallorca, 29 de abril 1976.

Sr. D. Alberto Sánchez

Alcalá, 323

Madrid - 27

Mi gran amigo:

Como que desde mi última carta hasta la reciente de $\mathrm{Vd}$. del 25, inclusive, que recibí hace dos días, se me van perfilando muchos detalles concernientes a mis proyectos, bueno será que, haciendo una vez más uso de mi modo de proceder sistemático, aún a trueque perder espontaneidad, conteste la presente por medio de sus correspondientes apartados.

$1 .^{\circ}$ y más urgente: las reuniones bibliográficas.

Como siempre, ha sido la carta de Vd. oportunísima en tiempo y modo, pues, bien mirado, buena la hubiésemos armado, Vd. con su afán de complacerme y yo con el de apresurarme en el desarrollo de mi idea, si de buenas a primeras se me hubiera endilgado a mí, inexperto en estas lides, una ponencia sobre tema que, aunque presumo conocer un tanto, está aún para mí más necesitado de consejeros censores que de oyentes. Exponer una idea, un plan, un proyecto, de buenas a primeras y ante una selecta concurrencia de maestros y doctores, sin haber compulsado previamente el parecer de los más sabios y experimentados, y hecho ello aún por un innominado cuya única credencial es la de ser un cervantista bibliógrafo aficionado, me parece que es tanto como salir a la palestra con ganas de cosechar, como fruto más leve, canastas de indiferencia. Y aunque suponga pensar un poco más como Sancho que como Quijote, praestat invidos habere quam misericordiam.

Cuando en mi última carta le decía, y era verdad, que deseaba ser invitado a estar en reuniones, tenía en mi ánimo conseguir, de momento, dos únicas finalidades, a saber: autorización para asistir a ellas, siquiera como simple oyente, y oportunidad de exponer mi proyecto, pero no en forma de ponencia sentenciosa, sino más bien en plan amigable y coloquial con quienes, eruditos e investigadores, hubieran asistido y pudieran ser útiles, 
a juicio de Vd. siempre, a mi proyecto. Nos decía Pi Sunyer, catedrático de administrativo, y que era o había sido secretario de alguna gran corporación municipal o provincial, y además lo decía con su habitual gracejo, que sabía bien por experiencia propia que los grandes asuntos o problemas del municipio eran más querenciosos a la componenda en el café de al lado y ante una taza de buen café que en las protocolarias sesiones a que la ley los sometía. A fin de cuentas, pues, la respuesta del Sr. Simón Díaz ha sido providencial para no echar al traste, con precipitaciones poco diplomáticas, el proyecto. ¿No lo cree Vd. también así?

Entiendo, eso sí, que se me autoriza a asistir a estas reuniones, que, ya puede Vd. suponerlo, van a ser para mí interesantísimas. Y en esta inteligencia pienso estar en Madrid, si no los tres días completos (tengo muchos jaleos armados aquí), sí por lo menos los dos con ponencias más prometedoras. Que son, desde luego, la de Vd., la de «Cervantes en Bulgaria» y la del Sr. Porqueras. ¿Podría, a este respecto, enviarme una fotocopia del programa establecido a fin de distribuir mi tiempo?

$\mathrm{Y}$ entiendo también (corríjame si yerro) que se verá Vd. incordiado por mí en demanda de presentaciones de quienes puedan echarme una mano para el ulterior desarrollo del fomento de la bibliografía cervantina. En una palabra: que pueda relacionarme un poco debidamente al respecto. Como verá Vd. por lo que digo más abajo, ésta es la tarea más importante en estos momentos.

Al margen de todo lo anterior, y antes de pasar al segundo capítulo, quisiera que me contestara a una pregunta: ¿Es suficiente la calidad de bibliotecario o de amante de la bibliografía para poder asistir a estas reuniones? Digo esto (y de momento no me obligue Vd. a ser más explícito) porque el encargado de la Biblioteca March, en Palma (posiblemente una de las mejores colecciones regionales que pueda haber en España), acaso, si se lo digo (pero con nadie absolutamente he hablado de ello), me acompañe. Y a mí me interesa, por lo que pueda tronar el día de mañana, mantener buenas relaciones con tan poderosa institución. Vd. ya me entiende.

2..$^{\circ}$ en donde se expone el estado actual de mi proyecto.

Sin necesidad de exposición de motivos, diré que la cosa actualmente está como sigue:

${ }^{1}$ Se está gestionando ya la creación legal de una Asociación Bibliográfica Cervantina, con finalidades que se deducen claramente de su mismo nombre. Se denomina «asociación» y no otra cosa semejante como agrupación, grupo, sociedad, etc., no tanto para que se incluya dentro de la terminología propia de la reglamentación que va a ordenarla, como para seguir la corriente al uso en otras entidades de fines similares. Y la califico de «bibliográfica» aún consciente de que mejor quedaría diciendo «de»o «para bibliógrafos»; pero la misma corriente al uso y la mejor sonoridad de la expresión obligan a esta concesión. (Opino, por ejemplo, que el «Índice Histórico Español» incurre en este mismo error de expresión: debería ser «Índice de Historia de España» o «española». El índice se refiere a la historia, pero de sí no es histórico. Etc.).

Esta asociación la fundamos aquí entre tres o cuatro, que en eso la ley no es muy exigente. En cambio sí lo es desde el momento en que el campo de su actuación no es únicamente provincial, sino nacional; para lo cual la 
aprobación definitiva tiene que venir de Madrid. Esto retrasa unos meses la autorización legal definitiva.

Se había pensado en un principio en una fundación de las que la ley llama «benéfico-docentes». Pero por el momento me aparto de tal idea porque las exigencias legales son ya más rígidas y se necesita, para no hacer el ridículo, una cierta importante donación. Y porque siempre queda la posibilidad el día de mañana si conviene, de convertirnos en sociedad de este tipo, en especial por las desgravaciones fiscales que a los miembros pueda suponerles y por las ayudas económicas (económicas sólo, jamás administrativas) que puedan solicitarse del Estado.

2 Tengo ya editor, presupuesto, estudios de formato, etc., y subvención asegurada para dos o tres años, para la revista que sea portavoz de la asociación y preceda, primero, y acompañe, luego, la labor propia del archivo cervantino.

Características, en síntesis: trimestral, $25 \times 17 \mathrm{~cm}$, no más de 300 págs, buen papel apto para reproducciones facsimilares. Aparte los honorarios por colaboraciones, que desconozco en absoluto (y qué bueno sería, y por qué no, obtenerlas desinteresadamente), si se tirasen 1.500 ejemplares y se vendiesen 1.200 (los 300 restantes para canje con otras revistas y envío a los colaboradores fijos), con 600 ptas. al año se cubrirían gastos de impresión, distribución, carteo, etc. Quedarían los gastos oficinescos o de organización (secretaría, correspondencia, etc.), para los cuales, repito, tengo dos o tres años cubiertos. Después, como no me canso de repetir, ya Dios dirá. A veces hay que echarse al ruedo confiando en que Dios repartirá, siempre, suerte. El simple hecho de ponerse a meditar para asegurar la pervivencia de tamaña empresa más de dos o tres años, me parece sencillamente bochornoso. Confío que en España debe quedar aún un grado suficiente de amor a nuestra cultura para no dejar fenecer una empresa como la que expongo. No quiero ni siquiera dudarlo, porque aquí sí que sólo la duda ofende. (Pero, desgraciadamente, no puedo olvidarme de la moraleja del cuento de Eugenio d'Ors: voy de caza y el ave, que huye del lugar, presagia allí tormenta; mato al ave y me libro de su mal presagio, pero no consigo librarme de la tormenta).

$\mathrm{Y}$ tengo, incluso, quien está dispuesto a trabajar y llevar a su cargo todo lo administrativo de la revista; inteligente y con dominio de cinco idiomas.

${ }^{3}$ Ahora bien: todo esto, que parece, y aunque se le dosifique masivamente todo el entusiasmo que la empresa pueda despertar, un poco de algo, es, no obstante, nada, desde el mismo momento en que falta aún la colaboración científica necesaria para que pueda salir, al menos, el primer número. Es como sí, teniendo todos los eslabones a punto, no tuviese lámpara que colgar de la cadena.

Y esto no puede conseguirse, si se pretende empezar y seguir con éxito, más que a base de firmas prestigiosas en el campo de los estudios cervantinos que se avengan a colaborar. De hecho los «sé» todos y de hecho no «conozco» a ninguno, más que a Vd. Y aunque lo considere a Vd. (y le aseguro que no es falsa adulación) el más calificado en la materia específica de esta nascitura publicación periódica, sé también que solos Vd., con aportación de su ciencia, y yo, con la de mi entusiasmo, no iríamos a ninguna parte. Ni aunque doblásemos la capacidad de Menéndez Pelayo. 
Mi intención resulta, pues, evidente: partiendo de Vd. (y perdóneme si indirectamente vengo a calificarle de trampolín), tenemos que llegar a relacionarnos, a ponernos en contacto con todos los que Vd. mismo juzgue más oportuno tener a nuestro lado. ¿No le parece bien la idea?

Y así y todo surgen a la fuerza varias interrogantes: ¿Cómo organizar esta tarea? ¿Por quién empezar? ¿Qué personalidades, qué centros culturales van a responder a nuestra llamada? ¿Se anuncia la cosa con una propaganda de corrida de toros o, por el contrario, solapadamente, langsam und sicher, como me decía mi maestro de alemán?

En todo esto sí que de verdad necesito consejo, cuánto más prudente y experimentado mejor. Y de todo ello pienso tratar, si Vd. me lo permite y me depara ocasión para ello, en Madrid, con Vd. mismo primero y con quien tenga $\mathrm{Vd}$. la amabilidad de relacionarme.

${ }^{4}$ El contenido de esta revista, cuyo título puede estudiarse luego, es, como puede $\mathrm{Vd}$. suponer, limitado a los fines propios de la asociación: en realidad una ampliación, una tendencia a la exhaustividad, de la magnífica labor que realiza Vd. en los Anales Cervantinos, con inclusión de artículos especializados en el estudio de la difusión de Cervantes por países, por épocas, etc., o sobre bibliotecas, etc., etc., sin olvidar, naturalmente, el poder de dar cabida, a guisa de excepción, a otros artículos de fondo.

3. ${ }^{\circ}$ más personal.

Concluenda est, mi querido don Alberto. Estoy seguro de que sus discípulos se merecen más atención que yo. Déjeme, no obstante, acabar saliéndome un poco del tema.

${ }^{1}$ Por aquí salió, con ocasión de la Fiesta del Libro, y con anuncios incluso en los periódicos, «El tesoro mágico de Don Quijote de la Mancha» por Damián Estades Rodríguez, Madrid, 1976, sin apadrinamiento de editorial pero impreso por Ornigraf-Arsango, tamaño $238 \times 168 \mathrm{~mm}, 426 \mathrm{pp}$ $+3 \mathrm{~h}$ y en rústica, que, Dios y cielo santos, han constituido el más ingrato dispendio de quinientas pesetas, menos su $10 \%$, que jamás me haya costado una obra cervantina. Si tuviese que reseñarla me vería en apuros. Prefiero dejarlo sin más comentarios.

${ }^{2}$ El Dios dispone de siempre malogró mi ida a Italia. Cuando ya había convencido a mi mujer, he aquí que, cual si hubiesen obedecido al unísono a un diabólico conjuro, tres o cuatro desaprensivos (y deudores de cierta categoría) prefirieron dejarse protestar sus letras antes que pagármelas, con el consiguiente malestar y la incordiadora pupa que puede Vd. imaginarse, $\mathrm{y}$, encima, otros cuantos asuntos judiciales, que parecían adormilados, despertaron después del letargo de la semana pascual; y no hubo más remedio que, aparte de paciencia y barajar, hacer frente a los primeros y atender a los segundos. Debe Vd. creerme, porque es verdad, si le digo, como hago, que en este instante son las cuatro y cuarto de la madrugada; que el trabajo de ayer ha acabado hoy pasada la medianoche con una junta de copropietarios (cuarenta iguales gritaría el de los ciegos) cada cual con su pretensión individual a cuestas; que apenas he malcenado en casa; y que en acabando la presente me espera aún la tarea de ordenar y proveer lo de mañana, digo ya hoy, apenas el rubicundo Apolo etc., que aquí, obedeciendo siempre a Kepler, sale veintitantos minutos antes que en Madrid. Siempre he comprendido, cómo no, las últimas tentativas de don Quijote en unos momentos en 
que, cansado y apenado de un cierto espíritu derrotista, quiso refugiarse en la vida pastoril. (Puedo demostrarle que en cuanto a la hora en que escribo la presente no falto a la verdad: en estos momentos la Radio Nacional está dando el «Don Quijote» de Telemann.) Hace cuatro años adquirí una finca, totalmente improductiva, pero de casi $100 \mathrm{Ha}$, de montaña y en el lugar más privilegiado en cuanto a tranquilidad y buena panorámica de Mallorca. Con decirle que fue ermita de los trapenses cuando estuvieron aquí está dicho todo. Pues bien: no he podido disfrutarla más que seis o siete horas cada dos o tres meses. Y que Dios me conserve la salud.

Me he ido por los cerros de Úbeda y le he puesto a Vd. en trance de echar pestes de mi pertinaz verborrea. Acabo, no sin antes suplicarle una vez más, a los fines de lo dicho arriba, que me envíe, si puede, cuanto antes fotocopia del programa de las reuniones cervantinas.

Siempre atto. afmo., etc., etc.

JMCasasayas

\section{Contestación de 6 de mayo de 1976}

Como tiene prisa D. Alberto por marchar de Madrid, le escribe para indicarle que podrá José María asistir como oyente a la reunión bibliográfica. Le informa de I Congreso Internacional de la Picaresca (del 21 al 27 de junio) donde se leerán dos ponencias cervantinas, así como exponer ante otros profesores el proyecto de la Asociación Bibliográfica Cervantina.

6 de mayo 1976

Sr. D. José M. ${ }^{\text {a Casasayas Truyols }}$

Palma de Mallorca

Querido amigo:

Recibí su amable carta del 29 de abril, recién pasado, y le contesto con urgencia, pues me voy a un largo viaje este fin de semana y no quería demorar por más tiempo el envío de la fotocopia que $\mathrm{Vd}$ me solicita con el programa de las próximas reuniones bibliográficas (demasiado próximas para mí, que no he empezado a redactar todavía mi ponencia).

A tenor de lo que me decía en su carta Simón Díaz, con el que no he podido hablar personalmente todavía, creo que no habrá dificultad para que asista en calidad de oyente su amigo bibliotecario, puesto que al no haber establecido lo de que las reuniones sean cerradas, mientras haya espacio, supongo podrá admitirse la presencia de los interesados por estos temas que, naturalmente, no atraen a tanto público en nuestro tiempo como el fútbol, los toros o las discotecas.

Ahora acabo de recibir otro programa impreso con las ponencias del I Congreso de la Picaresca, que se celebrará en Madrid, Hita y Guadalajara durante los días 21 al 27 de junio siguientes. Encuentro anunciadas SEIS ponencias cervantinas: cuatro son de profesores de Universidades norteamericanas y dos españolas (la de Fernando Lázaro, académico de la Española y catedrático de la Universidad Autónoma de Madrid, y la mía). 
Como verá, no faltan alicientes para terminar el curso animadamente. Tengo que felicitarle por la decisión y feliz iniciativa de emprender esa nueva Asociación Bibliográfica Cervantina de que me habla, con su portavoz que ponga en marcha su acariciado y generoso empeño del archivo de que hablamos y al que me referiré en la ponencia, pues ya recibí la bendición aquiescente del promotor.

También he leído el suelto que me remitió de La Vanguardia, con la bochornosa noticia — que ya no debe sorprendernos-, una más en el mundo «cultural» de nuestra patria.

Cordiales saludos de su buen amigo

Alberto Sánchez.

Carta quinta: $11-V-1976$

Escrita en tono humorístico el soneto («Perdone Vd. el ripio: [...]»), indica fecha posible de su viaje a Madrid.

Palma de Mallorca, 11 de mayo 1976.

Sr. D. Alberto Sánchez

Alcalá, 323

Madrid - 27

\section{SONETO}

El lunes, veinticuatro, don Alberto, y por la tarde, tengo una asamblea con una empresa que, maldita sea, por mal traer me trae a peor puerto. Si no puedo cambiar la fecha, advierto que habré de malograr mi buena idea de presenciar completa la tarea de ese bibliográfico concierto ${ }^{1}$. Mas como quiera que es mi intento ufano y en ello tengo, más que empeño, ahínco, si no se opone el cielo soberano pienso ir a Madrid del primer brinco de la celeste Iberia, el más temprano del otro día, martes, veinticinco.

\section{Casasayas.}

${ }^{1}$ Lo que me hará perder la extraordinaria ponencia de «Cervantes en Bulgaria».

(Perdone Vd. el ripio; pero me acojo a la ventaja que me proporciona el soneto, limitado a su extensión de los 14 versos.)

No hay respuesta. 
Carta sexta: $19-V-1976$

Está relacionada con un documento notarial con la firma de Cervantes (había duda entonces de su originalidad), texto transcrito con variantes en el libro de José María Asensio y Toledo (Sevilla,1864). Lo adquirió Casasayas a un coleccionista de Palma, cambiando libros que le interesaron a este de la biblioteca de José María. Al final comento algo de la historia que siguió el documento.

Palma de Mallorca, 19 de mayo 1976.

Sr. D. Alberto Sánchez

Alcalá, 323

Madrid - 27

Mi estimado y admirado amigo:

Hace unos días llegó a mi poder el documento que por fotocopia de sus dos caras va adjunto.

Después de haber dado fin a su trabajosa lectura, mediante Dios y ayuda (pues soy un ignorante total en paleografía), vine a caer en la cuenta de que se trata del mismo documento que don José M. Asensio y Toledo publicó en sus «Nuevos documentos para ilustrar la vida de Miguel de Cervantes Saavedra...». Sevilla 1864, apartado X, págs 30-31, pero con unas salvedades para mí irritantes: la de que hay algunas esenciales diferencias entre lo que leí y lo que transcribió Asensio. Pues, aparte el desarrollo de las abreviaturas que ya advierte Asensio en el prólogo, es extraño, por ejemplo, que donde el documento dice «Miguel de ceruantes saabedra» la transcripción de Asensio diga «Miguel Cervantes de Saavedra»; que donde el documento dice (líneas 20-21) «en vte e quatro de otubre», Asensio transcriba «en veinte y cuatro días del mes de octubre»; que donde el documento dice (líneas 25-26) «de que me doy por contento y pagado», Asensio lea «de que me doy por pagado y contento»; que donde el documento dice (reverso, línea 4) «en Seuilla a ocho dias», Asensio suprima la preposición; y que, finalmente (y aparte otros detallitos) Asensio no haga constar el tachado de «prouision» por el interlineado «comision», que en la línea 17, y la correspondiente salvedad de la enmienda al final del texto del documento, que éste contiene.

Se me ocurre preguntarle a Vd. (otra molestia más) su opinión al respecto. ¿Se trata, el que yo tengo, de una falsificación, en donde el falsificador, conociendo la transcripción de Asensio por supuesto, cometió adrede estas divergencias como queriendo demostrar precisamente la libertad que Asensio se tomaba en la transcripción de los documentos?

He comprobado personalmente las firmas de Cervantes y de los escribanos del documento con otras de los mismos obrantres en los facsímiles que Astrana Marín publica en su monumental Vida de Cervantes, y, por la poca experiencia que tengo en casos judiciales de comprobaciones de firmas, podría jurar que o son auténticas o la falsificación es estupenda. 
Asensio no dice en el prólogo de su obra a quién pertenecían estos documentos que transcribe. Sólo se refiere que adquirió, «mediante un sacrificio pecuniario», el Libro de retratos de Pacheco. Y el «Catálogo de la biblioteca cervantina de don José M. ${ }^{\mathrm{a}}$ de Asensio y Toledo», de Miguel Santiago Rodríguez, Madrid 1948, que advierte que la colección la conserva la familia, no menciona documentos algunos como existentes en la biblioteca. Por otra parte Astrana Marín, en el tomo V, p. 77, de la «Vida ejemplar...», etc., transcribe parte de este documento pero siguiendo al pie de la letra el texto de Asensio, al que cita en nota. No debió ver el original (o el original es distinto del que yo poseo).

Pregunto: si el documento es auténtico, ¿cómo, después de haber pasado por manos tan cuidadosas y eruditas de cervantista ilustres, ha llegado hasta aquí?

¿Son frecuentes las falsificaciones con la artimaña que, de serlo el presente documento, presenta?

Le dejo con ella tema de estudio, si el tiempo y las demás ocupaciones se lo permiten.

Si cree interesante ver el documento original que poseo, dígamelo, si no hay tiempo por carta, por teléfono, y se lo traeré el martes 25 , en que iré a Madrid, tal y como anunciaba en mi festivo soneto.

Siempre afectuosamente.

Casasayas

No hay respuesta.

\section{Carta séptima: $28-V-1976$}

Breve escrito para excusarse por qué abandonó Madrid con prisa tras asistir a las conferencias de la Fundación Universitaria Española en Madrid. Cuando José María se jubiló de su despacho y quehaceres fue cuando pudo atender al proyecto de la Asociación de Cervantistas.

Palma de Mallorca, 28 de mayo 1976.

Sr. D. Alberto Sánchez

Alcalá, 323

Madrid - 27

Mi estimado amigo:

Apenas acabó su magnífico parlamento el Sr. Sainz Rodríguez, tuve que salir pitando para el aeropuerto para no perderme el avión de regreso a casa.

Sentí no poder agradecerle personalmente la "propaganda» que hizo Vd. de mí y lo halagado que me sentí por ello. Se lo digo ahora.

Entre el 13 y el 20, salvo contraorden, estaré en Escocia. Pienso ir a visitar a Mr. Riley en Edimburgo, a ver si hay suerte. Si quiere Vd. algo 
de él, pues sé que les une gran amistad, dígamelo sin reservas algunas. Tengo que ir hasta Inverness y, como es natural, voy a intentar la suerte con lo del monstruo.

Siempre a su disposición, afmo.,

Casasayas

\section{Contestación del 2 de junio de 1976}

D. Alberto se refiere al viaje próximo de José María a Escocia. Escribe de la preparación del volumen XV de Anales Cervantinos y menciona la biblioteca de D. Miguel Bordoy, también coleccionista de objetos cervantinos (más bien lo segundo).

2 junio 1976

Sr. D. José M. ${ }^{a}$ Casasayas

Palma de Mallorca

Querido amigo:

Recibí su amable carta del 28 de mayo ppdo., que me apresuro a contestar ante la inminencia del viaje a Escocia que me anuncia. Buena envidia que me da, porque Escocia, de todos mis recorridos fuera de España, es de donde guardo más gratos recuerdos y no quisiera irme de este mundo sin volver por allí. Si viera usted al profesor Riley le saluda muy cordialmente de mi parte y le dice que aguardo nuevas colaboraciones suyas para Anales Cervantinos.

De momento estamos preparando ya el vol. XV (la parte mía es la más atrasada). Tengo entre manos ahora mi contribución al homenaje del cervantista Moreno Báez y mi ponencia (ya enviado el resumen) para el I Congreso Internacional de la Picaresca: las dos de tema cervantino.

Le desea un viaje feliz y le saluda con todo afecto

Alberto

¿Estará Vd en Palma durante el mes de julio? Estoy estudiando la posibilidad de ver los libros de Bordoy...

Alberto 